\title{
Working Memory and ADHD in Preschool Education. The Role of ICT'S as a Diagnostic and Intervention Tool: An Overview
}

\author{
http://dx.doi.org/10.3991/ijet.v10i5.4359 \\ Georgia K. Kokkalia, and Athanasios S. Drigas \\ NCSR DEMOKRITOS, Institute of Informatics and Telecommunications, Net Media Lab, Athens, Greece
}

\begin{abstract}
Recent development in the role of education in pre-school children includes the use of Information and Communication Technologies (ICTs). ICT nowadays is recognized as a tool that can foster the knowledge and the experiences for this crucial age and the support of specific areas in kindergarten according to the educational perspective and the areas of needs they serve, is thought significant. In this paper we present a brief overview of the most representative studies of the last decade (2004-2014), which concentrates on the working memory and attention difficulties that children face in kindergarten, and are supported by ICTs. A brief theoretical scientific approach of the role of working memory is presented while its correlation with the Attention Deficit Hyperactivity Disorder (ADHD) is examined.
\end{abstract}

Index Terms-Working memory, preschool education, Attention Deficits, ICT.

\section{INTRODUCTION}

Recently, there has been an increasing emphasis on educating people who need special education with the support of ICT and thus this fact has reinforced the use of technology as a mean of overcoming barriers to their learning. There is now a general agreement amongst different specialists that ICT can support a child's skills as well as can create a developmental appropriate learning environment depending on their needs and the curriculum requirements [1]. Existing studies on the introduction of ICTs in special education argue that can provide children with additional opportunities for rich learning activities that are relevant to their growth characteristics and have positive effects in regard to their learning difficulties [2]. As a result, ICT can play an essential role in achieving the goals of the curriculum in all areas and subjects if the provided developmentally appropriate software applications are embedded in appropriate educational scenarios. Additionally, it has been noted that children who are exposed to high quality learning opportunities experience less difficulties at their academic life [2].

However, not all learners meet the same needs. That means that there are groups that face certain difficulties, which can lead to serious consequences for academic performance as well as for relationships and occupational outcome [3]. Today, hundreds of experts in the fields of medicine, education and psychology are encouraging working memory training and they've done an important approach into practices and schools helping people of all ages who face difficulties because of poor working memory. Researchers agree, that working memory is central to cognitive skills and is closely correlated to academic and professional life. Moreover, working memory is the term used to refer to a higher-order skill to allocate attentional resources despite distraction or interference and increases considerably throughout childhood [4]. However, poor working memory is the source of many problems related to attention and is often linked to Attention Deficit/Hyperactivity Disorder (ADHD).

ADHD is a psychiatric diagnosis that identifies children who exhibit inappropriate levels of inattention and/or hyperactivity [5] and is associated with poor scholastic outcomes or other learning disabilities [6]. Attention difficulties are one of the most prevalent problems that become apparent during a child's school-life and are usually characterized by poor attention skills and/or hyperactive and impulsive behaviours. These problems usually show up in early childhood and more specifically are present before the age of seven where often a diagnosis is taken place. A common misconception about children with attention problems is that they aren't paying attention and they cannot focus on a specific time for an acceptable period. This elevated risk for poor academic achievement indicates that many students with attention disorders are in need of an accurate diagnosis and effective intervention strategies as ADHD usually continues into adulthood [7]. Research suggests that successfully management and behaviour modification of this disorder often depends on the integrated program of medical interventions and behavioural techniques. A very important factor for this purpose is to involve parents and teachers in these interventions [8].

As a result, a growing number of studies seem to support the use of ICTs in both mainstream and special education with several ways such as alternative communication, assistive or enabling technology, Internet applications, virtual environment and technology integration [9]. However, it is well known that computerized programs seem to be a promising new approach to memory interventions as the role of technology for people with cognitive difficulties is crucial in the areas of based applications and neural networks [10].

Our scoping study drew upon national and international publications as well as the research findings of the most representative studies of the last decade which focus on the use of ICT in the preschool age as a diagnostic and intervention tool in children who face memory difficulties and are struggling with ADHD. A brief theoretical approach of the role of working memory and its correlation with the ADHD is also examined. This paper will present a brief overview of the most representative studies that 
introduce software applications programs for diagnosis and intervention purposes of preschoolers who face working memory and attention difficulties and need assessment while a short theoretical scientific background is introduced.

\section{A BRIEF THEORITICAL APPROACH OF WORKING MEMORY}

Over the last 40 years, the concept of working memory has been used widely, extending from cognitive psychology to many areas of cognitive science and neuroscience. The term of working memory was presented around 1960 [11], adopted as the title for a multicomponent model by Baddeley and Hitch and was used independently by Olton in connection with the performance of animals [12]. According to Klinberg [13], working memory refers to the system or systems that are assumed to be necessary in order to keep things in mind while performing complex tasks such as reasoning, comprehension and learning. Also, working memory is related to the hold of information over a brief period of time, a function that is of central importance for a wide range of cognitive tasks and for academic achievement. Moreover, the concept of working memory evolved from that of short-term memory to the temporary storage of small amounts of material over brief periods of time. As it was mentioned, it became a topic of major interest during the 1960s and was linked to an information-processing approach to psychology, in which the digital computer served as a theoretical basis for the development of psychological theories and as a result this approach became known as cognitive psychology. However, investigating the multicomponent concept of working memory for more than 30 years this fact developed a useful theoretical framework for human activities and at the same time generated progress in understanding the role of memory in human's capacity to think [14].

According to Baddeley et al. [15], the dominant conceptualization of working memory is of a system comprising multiple components whose coordinated activity provides the capacity for the temporary storage and manipulation of information in a variety of domains, consisted of four limited capacity elements. The central executive is a domain-general component responsible for the control of attention and processing that is involved in a range of regulatory functions including the retrieval of information from long-term memory. The temporary storage of information is mediated by two domain-specific stores the phonological loop that provides temporary storage of verbal material, and the visuo-spatial sketchpad that specializes in the maintenance and manipulation of visual and spatial representations. The fourth component, the episodic buffer, is a relatively new component of the working memory model.

Many researchers agree that working memory (WM) capacity predicts performance in a wide range of cognitive tasks. Although WM capacity has been viewed as a constant trait, recent studies suggest that it can be improved by adaptive and extended training. This training is associated with changes in brain activity as well as, with changes in dopamine receptor density. Nevertheless, the observed training effects suggest that WM training could be used as a remediating intervention for individuals for whom low WM capacity is a limiting factor for academic performance or in everyday life [16].
Taking the above into consideration, many studies show that conservation of information in WM is associated with elevated and sustained neural firing over a delay when information is kept in mind [17]. Neuroimaging studies in humans have mapped WM-related activity to both sensory association cortices and prefrontal cortex. Moreover, impaired WM is observed in many neuropsychiatric conditions, such as attention-deficit hyperactivity disorder (ADHD). As a result it is not surprising that attempts to improve WM have a long history, beginning with Earl Butterfield and colleagues (1972) who reported a series of studies attempting to improve short-term memory in learning-disabled individuals by teaching participants to use sub-vocal rehearsal strategies. Besides, this approach led to some improvement in participants' performance there was no evidence of transfer either to non-trained cognitive tasks or to everyday performance [18].

Finally, it must me noted that mapping of the neural activity during WM tasks to specific psychological terms is still work in progress. Psychological models of WM distinguish sensory-specific storage from a coordinating or controlling function, referred to as the central executive or controlled attention. Attention is thus closely linked to WM. Controlled attention usually has to do with the voluntary allocation of selective attention and relies on parietal and prefrontal regions that overlap with activation during WM tasks in both the parietal and prefrontal cortex. Control of attention is necessary in WM tasks; conversely, retention of an internal representation of a salient location in WM is crucial for directing and maintaining attention towards that location. The neural basis for WM and controlled attention might thus rely on the same mechanisms of sustained neural activity and top- down excitation, and the same multi-modal front-parietal network, and might be difficult or impossible to separate even at the neuronal level [19].

\section{THE CORRELATION BETWEEN WORKING MEMORY AND ATTENTION}

Attention and memory are two important cognitive abilities. Whereas selective attention determines how limited mental resources are allocated to the most important piece of information in the surroundings, memory keeps this information in order to allow past experience to guide future behaviors. Although the two abilities appear to occur at different stages of information processing, and so each of them has their own research tradition, recent research has shown that they may be more intertwined than has been previously considered [20].

With regard to the relationship between attention and memory, recent research has proved that memory may affect the way that visual spatial attention is allocated. On the other hand, the inhibition effect is noticed when memory of past visited locations prevents attention from visiting these locations again. This inhibitory memory mechanism seems to improve visual search efficiency, claiming that memory plays a role in attentional allocation [21]. In addition to inhibitory, visual working memory also influences allocation of attention and biases attention towards a location that contains a memorized visual item [22].

The relationship between visual attention and working memory has also been examined by looking at whether working memory is important for attentional tasks. One way to achieve this is to observe whether filling up working memory to its capacity impairs an attentional work. 
PAPER

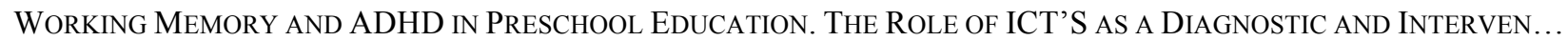

Reduction in efficiency of attentional allocation here would mean that working memory is required for the attentional ability, and this can be measured by the visual search paradigm. In a visual search task, participants discern the presence or the identity of a predefined target among a number of distractors. In a serial search, in which attention is asked to distinguish a target from a distractor, reaction time typically increases linearly with the number of total search items. This search slope is a measure of visual search efficiency. By comparing serial search efficiency during the retention interval of a working memory task with a situation with no memory burden, it was found that visual search does not require visual working memory [23] or verbal working memory. However, visual search efficiency is impaired by executive working memory load and spatial working memory load [22], suggesting that executive working memory and spatial working memory are important for allocation of attention.

According to Unsworth \& Spillers [24] there is a wellestablished relationship between working memory capacity and attentional control. Attentional control refers to the ability to direct attention toward goal-relevant information and away from strong distraction. Relative to people with low working memory capacity, individuals with high working memory capacity are less likely to have their attention inappropriately drawn into strong distraction, such as hearing their own name or responding to a peripheral flash [25]. In addition, individuals with high WM capacity are less prone to mind-wander when focus is needed [26]. Thus, in addition to the potential to improve reasoning ability, WM training may help people become more attentive in their daily activities.

It is critical for the present discussion to note that children with low WM capacity are prone to learning disabilities and have difficulty carrying out complex instruction [27]. A specific area of interest to training researchers is attention-deficit/ hyperactivity disorder (ADHD). Although the distinction between ADHD as it relates to deficits of attention and presence of hyperactivity is controversial [28]. Diamond et al., [29] argued that low WM capacity is symptomatic of attention deficits. From her perspective, ADHD-diagnosed children who specifically show symptoms of attention deficits (absent hyperactivity) are experiencing WM-related deficits of selective attention (i.e., attentional control). Hyperactivity, on the other hand, is assumed to stem from difficulty with response inhibition.

As a result, this perspective [29] suggests that effective WM training should specifically alleviate deficits of attention, but not tendencies toward hyperactivity. Westerberg, Hirvikoski, Forssberg, and Klingberg [30] however, have demonstrated that, regardless of presenting-symptoms, ADHD is generally associated with visuo-spatial memory deficits as well as difficulty in consistently allocating attention to a task. Thus, an intervention that strengthens the core functions of WM may be beneficial to all individuals with ADHD.

\section{SUPPORT PRESCHOOL CHILDREN WITH WORKING MEMORY PROBLEMS}

According to the National Joint Committee on Learning Disabilities [31], early indicators for learning disabilities may include delays in speech and language development, in cognitive and motor skills, difficulties with the social interaction, and other learning areas relevant to the educational goals. These indicators may occur with problems in self-regulation, attention, or social interaction. In precise, research has supported that children at young ages show advanced cognitive capacities through computer-based activities as, they develop their memory, their attention, their literacy abilities, their mathematical thinking, the development of their concentration and motivation to learn and complete tasks, their problem solving capacities and consequently their school achievement [32]. Additionally, multimedia technology can provide children with learning difficulties the appropriate reinforcement in order to achieve the better result for them as it offers the opportunity of presenting information in both verbal and pictorial forms, enabling students with learning disabilities for a deeper understanding of more meaningful connections between visual and verbal arrangements [33]. Nowadays, hundreds of experts in the areas of medicine and psychology are encouraging working memory training. They've brought an important approach into practices and schools around the world and are helping people of all ages succeed in areas of their lives that are characterized by poor working memory [34]. Working memory is thought central to concentration, problem solving, and impulse control, is closely correlated to fluid intelligence and is a strong indicator of academic and professional success.

Taking the above into consideration, in a current study, Alloway presented the Automated Working Memory Assessment (AWMA), a standardized computerized tool that can diagnose memory problems. This tool enables teachers and psychologists to assess memory skills with a user-friendly interface. AWMA includes three levels of assessment and is designed for students with suspectedespecially- working memory difficulties. General speaking, AWMA is a computer-based assessment that provides three measures each of verbal short-term memory, visuospatial short-term memory, verbal working memory, and visuo-spatial working memory. Specifically, AWMA Short Form (AWMAS) is used for assessing learners who probably have memory problems, nevertheless, the specific area of their problems has not been recognized and AWMA Long Form (AWMA-L) which is suitable for confirmation of working memory problems for learners identified as having working memory problems in the classroom [35].

Furthermore, according to St Clair- Thompson [36] one way of providing memory strategy training is to involve computer-based teaching and practice of memory strategies. The aim of a recent study was to explore a method of improving working memory, using a specific memory strategy training [37]. Children aged five to eight years were tested on measures of, visuo-spatial sketchpad, central executive components and the phonological loop of the multiple component model of working memory. A group of children also completed tasks of following instructions and mental arithmetic in the classroom, and standardized tests of reading, arithmetic and mathematics. Half of the children then used Memory Booster, a computer game that learns memory strategies, over a period of six to eight weeks. Memory Booster [38] is a pleasurable adventure game for children that teaches and encourages the use of imagination, the creation of stories and the development of cognitive skills while according to several studies results in significant improvements on working memory [37]. All the children were then retested on the memory and ability measures besides the standardized tests were administered later. The results showed that working memory strategy training has significant improvements in tasks assessing the phonological loop and 
PAPER

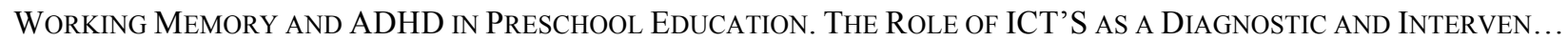

central executive components of working memory, and tasks assessing listening instructions and mental arithmetic in the classroom. However, there were not improvements on standardized tests of reading, arithmetic or mathematics, after the training and after the training of five months [37].

In addition, multiple assessments of both verbal shortterm and working memory are provided in a working memory test battery standardized for children [4]. The Working Memory Test Battery for Children- WMTBC [39] includes four measures of verbal short-term memory: digit recall, word recall, non-word recall, and word list matching recall. The four measures require verbal presentation of memory topics, with the first three tests requiring verbal recall. Word list matching implicates the child deciding whether two spoken sequences are right or not, as it sets minimal demands on phonological and articulator production skills. This test is particularly suitable for use with children with speech-motor deficits and scores are used to derive a standardized verbal memory score. The WMTB-C also has three measures of verbal working memory (verbal and counting recall, and backwards digit recall), scores on which are used to give a multiple working memory score. Lastly, the WMTB-C contains three measures of visuo-spatial short-term memory, which are matrices, mazes memory, and block, recall.

\section{SUPPORT PRE-SCHOOL CHILDREN WITH WORKING MEMORY PROBLEMS AND ATTENTION DEFICITS}

Early identification and intervention for children with memory problems has been strongly recommended. Professionals in psychological, medical, scientific, and educational fields have documented the importance of the years between birth and five years, for learning. If there is any risk of difficulties, these early years become even more critical [40] as there is a history of research supporting the value of early identification and intervention. One value of early identification and intervention is that it provides a base for later learning and could thereby raise later academic success experiences for children at risk. In addition, early identification can prevent secondary problems from occurring because it prevents the need for more extensive education services in the future and leads to more inclusive programming [41]. Poor working memory is the source of many problems related to attention and is often linked to Attention Deficit Hyperactivity Disorder, and other learning disabilities [42]. As a result, recent years have seen a rise in the popularity of computerized working memory (WM) training programs to kindergarten children, because these interventions give promises of increased IQ, creativity, grades and reductions in day-to-day lapses of attention.

Certain tools for working memory training have been developed and one of the most well-known intervention tools is Cogmed. This program has been marketed at schools to assist students' performance and is available as clinical practice for treatment of ADHD. Their developers claim that Cogmed training helps people to improve their cognitive and social skills included the attention and the working memory capacity. There are three types of Cogmed training; for preschoolers and older children which contains several visuo-spatial and verbal memory tasks that have been embedded in videogames, each of which is performed for roughly 40 min a day, 5 days a week, for 5 weeks. Cogmed JM and Cogmed RM are respectively designed for preschoolers and older children. Specifically, an example of a visuo-spatial task that is presented in Cogmed trainining, is "Asteroids" which presents a field of several free-floating asteroids, a subset of which lights up, one-at-a-time and the child must reproduce the sequence via mouse click. Additionally, an example of a verbal task is "Input Module" in which a sequence of auditory digits is played using a number-pad that is displayed on a robot's arm. However, although initial studies indicate that Cogmed is a successful intervention tool, there are some concerns about its validity and more research is need to be done. There are studied that state that Cogmed is an unsubstantiated tool and so the future research should place greater emphasis on developing theoretically motivated accounts of working memory training [34].

However, it is common knowledge that learning difficulties require special attention and as a result early education lays the grounds for future development. According to Galecka [43], Young Digital Planet started to create applications that were designed to help children restore their curiosity and keep learning engaging, motivating and challenging. Young Digital Planet supports the view that early prevention is very important; edu- Sensus is an intervention tool that is based on intuition, designed for speech therapists and combined with the educational needs communicated by the market. According to the developers, this software has been in use in Poland for almost 10 years now and has proven to be an irreplaceable tool for early education and special needs prevention. Specifically, eduSensus is a family of products addressing all developmental needs and one of the advantages is that it has been created together with therapists, teachers, parents and children. Moreover, eduSensus Team covers a wide range of topics in the use of ICT tools in supporting the development of children who face specific difficulties including children who are at risk of dyslexia and face other problems such as memory and attention deficits, developmental disorders etc. Lastly, the designers of the eduSensus claim that this platform introduces children into the ICT world develop young learners' vocabulary and communicative skills with digital programs, offering also effective and engaging stimulation of retarded children's development and support children who face learning difficulties at the kindergarten.

Moreover, Klingberg et al., [44] tested a computer program designed to improve working memory in children with ADHD. After 5 weeks of training, they observed positive effects on visuo-spatial working memory, verbal working memory, complex reasoning, and parent-reported symptoms of inattention and hyperactivity-impulsivity. Once again, there was evidence for transfer of training effects to non-trained skills and to observable behavior, which was still present when children were re-assessed 3 months following the intervention.

In the light of the above research, Holmes et al. [45] compared the effects of cognitive training to stimulant medication on working memory impairments in children with ADHD. With Baddeley's [46] model of working memory as the underpinning for the assessments used in this study, they found that cognitive training improved verbal, visuo-spatial, and executive aspects of working memory alike. Furthermore, the beneficial effects on executive working memory were apparent 6 months after the intervention was completed, while stimulant medication was associated with non-enduring improvements in visuospatial working memory. 
Also, Shalev et al. [47] studied computerized training for sustained, selective, orienting, and executive attention in children facing ADHD. They focused on the transfer of training effects to behavioral and school performance indices and found significant improvements in reading comprehension and passage copying, and in parent reports of inattentiveness.

Finally, Mezzacappa\& Buckner [48] suggest that school-based working memory training is considered very important for treating children with attention problems or hyperactivity. This approach may also overcome barriers to care delivery for economically disadvantaged children who are known to be at higher risk for poor school outcomes. According to their study, a computer program to train working memory for children with attention problems or hyperactivity was designed. Training was conducted daily for 5 weeks during school hours. Teachers evaluated children's behaviors before and after the intervention, and standardized assessments of verbal and visuo-spatial working memory were also conducted. The computer program that was used to train working memory, was 'RoboMemo' comprised eleven different exercises, five that trained visuo-spatial working memory, five that trained verbal working memory, and one that trained both domains of working memory. These exercises varied in their inherent complexity, and the program adjusted the level of difficulty for each exercise to the child's evolving ability. The researchers conclude saying that overall, children's behavior and working memory improved following training, compared to baseline and showed significant improvements.

\section{CONCLUSIONS}

During this review paper an attempt was made to present the significant role that ICTs play in dealing with working memory and attention deficits in preschool education. The scope of this study was to present if and how new technology can support kindergarteners who face memory problems and probably struggle with ADHD while a scientific theoretical approach of working memory and its correlation with ADHD was examined. Furthermore, intervention tools that enhance learning in children who have poor working memory and learning difficulties were described. The results of this small study suggest that training working memory in school settings may be a viable way to help children who struggle with attention problems or hyperactivity in the classroom. The findings of the studies we examined, which are the most representative studies over the last decade, showed that kindergarteners can benefit of the use of new technology and can gain many advantages and profits using the appropriate educational tools that offer the use of ICT. The use of ICT has also played a major part in shaping the knowledge and skills of school staff, therapists and special educators. As a result, diagnostic tools provide them with the possibility to employ different ICT strategies which might lead to an easier understanding of children's learning differences while ICT intervention tools support activities of kindergarteners' life. In addition, the strong connection between WM and ADHD suggests that WM improvement could also be valuable in decreasing ADHD symptom levels. However, this is still a relatively new area of research and it is for future studies to further investigate which cognitive functions can be trained and to what extent the effects of cognitive training can be generalized to other cognitive functions and behavior problems. However, there are also several fields that require further research such as investi- gations into the reliability and validity of the diagnostic ICT tools, adaptations of diagnostic and intervention tools to the various needs of students and therapists, and development of more ICT programs for the above areas in the specific crucial age. It is obvious that there is need for development and design of tools with the support of ICT's that helps children with memory problems as our study showed that there is place for such research while we did not have a satisfactory number of findings for this crucial age. Finally, we consider that the field of pre- school education and the interventions that ICTs can contribute in many areas of child's development calls for more investigation hoping that the results of the current study are encouraging. Besides, there is the general consensus that ICTs do play a significant role in both ensuring and enhancing learning skills of kindergarten children who face working memory and attention difficulties.

\section{REFERENCES}

[1] Plowman, L., Stephen, C.: Children, play, and computers in preschool education. British Journal of Educational Technology 36 (2), (2005) 145-157. http://dx.doi.org/10.1111/j.1467-8535.2005. 00449.x

[2] Westwood, P.: Teaching and Learning Difficulties: Crosscurricular Perspectives. Camberwell, ACER Press 2006.

[3] Meijer,C., Soriano, V., Watkins, A. : Inclusive Education across Europe: Reflections upon 10 Years of Work from the European Agency for Development in Special Needs Education. Childhood Education 83, (6) (2007) 361-374. http://dx.doi.org/10.1080/ 00094056.2007.10522951

[4] Alloway, T., Gathercole, S., Willis, C., Adams, A .: A structural analysis of working memory and related cognitive skills in young children. Journal of Experimental Child Psychology 87, (2012), 85-106. http://dx.doi.org/10.1016/j.jecp.2003.10.002

[5] American Psychiatric Association. : DSM 5. American Psychiatric Association (2013).

[6] Re, A. M.,Mirandola, C., Esposito, S. S., \& Capodieci, A.: Spelling errors among children with ADHD symptoms: The role of working memory. Research in developmental disabilities, 35(9), (2014) 2199-2204. http://dx.doi.org/10.1016/j.ridd.2014. 05.010

[7] Blurton, C.: New Directions of ICT-Use in Education. Learning without frontiers. UNESCO World Communication and Information Report, 2007.

[8] Finnis, J. : Myths and facts of learning technology. TechLEARNING. Retrieved March 6, 2004, from http://www.techlearning. com/story/showArticle.jhtml?articleID=22101447 2004.

[9] Tinio, V.: ICTs in Education. United Nations Development Programme, 2003.

[10] Drigas,A., \& Dourou,A. : A review on ICT based applications for intervention and assistance of people with memory deficits. I-JET 8, (2013) 1-3. http://dx.doi.org/10.3991/ijet.v8i5.3009

[11] Miller, G. A.: The magical number seven, plus or minus two: Some limits on our capacity for processing information. Psychological Review, 63, (1956) 81-97. http://dx.doi.org/10.1037/ $\underline{\mathrm{h} 0043158}$

[12] Butterfield, E. C., Wambold, C., \& Belmont, J. M.: On the theory and practice of improving short-term memory. American Journal of Mental Deficiency, 77, (1973) 654-659.

[13] Klingberg, T.: Training and plasticity of working memory. Trends in Cognitive Sciences, 14, (2007) 317-324. http://dx.doi.org/10.1016/j.tics.2010.05.002

[14] Baddeley, A.D.: Working Memory, Thought and Action (Oxford: Oxford University Press (2007). http://dx.doi.org/10.1093/ acprof:oso/9780198528012.001.0001

[15] Baddeley, A.D., Hitch, G.J., and Allen, R.J.: Working memory and binding in sentence recall. J. Mem. Lang. 61, (2009) 438-456. http://dx.doi.org/10.1016/j.jml.2009.05.004

[16] Repovs, G., and Bresjanak, M.: Special Issue: Cognitive neuroscience of working memory. Neuroscience 139, (2006) 1-413. http://dx.doi.org/10.1016/j.neuroscience.2005.12.007 
[17] Olesen, P. J., Westerberg, H., \& Klingberg, T.: Increased prefrontal and parietal activity after training of working memory. Nature neuroscience, 7(1) (2003) 75-79. http://dx.doi.org/10.1038/nn1165

[18] Klingberg, T.: Training and plasticity of working memory. Trends in cognitive sciences, 14(7), (2010) 317-324. http://dx.doi.org/10.1016/j.tics.2010.05.002

[19] Curtis, C.E. and D'Esposito, M.: Persistent activity in the prefrontal cortex during working memory. Trends Cogn. Sci. 7, (2003) 415-432. http://dx.doi.org/10.1016/S1364-6613(03)00197$\underline{9}$

[20] Chan, A. S., Cheung, M. C., Han, Y. M., Sze, S. L., Leung, W. W., Man, H. S., \& To, C. Y.: Executive function deficits and neural discordance in children with autism spectrum disorders. Clinical Neurophysiology, 120(6), (2009) 1107-1115. http://dx.doi.org/10.1016/j.clinph.2009.04.002

[21] Horowitz, T., \& Wolfe, J.: Memory for rejected distractors in visual search?Visual Cognition, 10(3), p. 257-298(2003) http://dx.doi.org/10.1080/13506280143000005

[22] Woodman, G. F., Luck, S. J., \& Schall, J. D.: The role of working memory representations in the control of attention. Cerebral Cortex, 17(2007) 118-124. http://dx.doi.org/10.1093/cercor/bhm065

[23] Vogel, E. K., Woodman, G. F., \& Luck, S. J.: The time course of consolidation in visual working memory. Journal of Experimental Psychology: Human Perception and Performance, 32(6), (2006) 1436-1452. http://dx.doi.org/10.1037/0096-1523.32.6.1436

[24] Unsworth, N., Spillers, G. J., \& Brewer, G. A.: Examining the relations among working memory capacity, attention control, and fluid intelligence from a dual-component framework. Psychology Science Quarterly, 4, (2010) 388-402.

[25] Burge, P., Ouellette-Kuntz, H., Hutchinson, N., \& Box, H.: A Quarter Century of Inclusive Education for Children with Intellectual Disabilities in Ontario: Public Perceptions. Canadian Journal of Educational Administration and Policy, 87, (2008) 1-22.

[26] Rieser, R.: Implementing inclusive education: a Commonwealth guide to implementing Article 24 of the UN Convention on the Rights of Persons with Disabilities. Commonwealth Secretariat (2012).

[27] Gathercole, S, Alloway,T., \& Pickering, S.: Verbal and Visuospatial Short-Term and Working Memory in Children: Are They Separable? Child Development 77, (2006) 1698 - 1716. http://dx.doi.org/10.1111/j.1467-8624.2006.00968.x

[28] Swanson,L., \& Kim,K. : Working memory, short-term memory, and naming speed as predictors of children's mathematical performance. Intelligence 35,(2007) 151-168. http://dx.doi.org/10.1016/j.intell.2006.07.001

[29] Diamond, A., Barnett, W. S., Thomas, J., \& Munro, S.: Preschool program improves cognitive control. Science (New York, NY), 318 (2007) 1387-1397. http://dx.doi.org/10.1126/science.1151148

[30] Westerberg, H., Hirvikoski, T., Forssberg, H., \& Klingberg, T.: Visuo-spatial working memory span: A sensitive measure of cognitive deficits in children with ADHD. Child Neuropsychology, 10(3), (2004) 155-161. http://dx.doi.org/10.1080/0929704 $\underline{0409609806}$

[31] Armstrong, D.: Reinventing 'inclusion': New Labour and the cultural politics of special education. Oxford Review of Education, 31 , (2005) 135-153. http://dx.doi.org/10.1080/030549804 2000337237

[32] Pickering,S. \&Gathercole, S.: Distinctive working memory profiles in children with special educational needs, Educational Psychology: An International Journal of Experimental Educational Psychology, 24, (2004) 393-408. http://dx.doi.org/10.1080/ 0144341042000211715

[33] Lee, L.\& O' Rourke, M.: Information and communication technologies: transforming views of literacies in early childhood settings. Early Years: An International Research Journal 26, (2006) 49- 62. http://dx.doi.org/10.1080/09575140500507835

[34] Shipstead, Z., Hicks, K., \& Engle, R. : Cogmed working memory training: Does the evidence support the claims? Journal of Applied Research in Memory and Cognition 1,(2012) 185-193. http://dx.doi.org/10.1016/j.jarmac.2012.06.003

[35] Alloway,T., Gathercole,E., Adams,A., Willis,C., Eaglen, R., Lamon, E.: Working memory and phonological awareness as predictors of progress towards early learninggoals at school entry. British Journal of Developmental Psychology 23, (2005) 417-426. http://dx.doi.org/10.1348/026151005X26804
[36] St Clair-Thompson, H.L: The influence of strategies upon relationships between working memory and cognitive skills. Memory 15 , (2007) 353-365. http://dx.doi.org/10.1080/09658 210701261845

[37] St Clair $\square$ Thompson, H.,Stevens ,R., Hunt,A., \& Bolder,E.. Improving children's working memory and classroom performance. Educational Psychology: An International Journal of Experimental Educational Psychology 30, (2010) 203-219. http://dx.doi.org/10.1080/01443410903509259

[38] Leedale, R., Singleton, C., \& Thomas, K.: Memory booster (computer program and manual) Beverly, East Yorkshire: Lucid Research (2004)

[39] Gathercole, S. E., Alloway, T. P., Willis, C., \& Adams, A. M.: Working memory in children with reading disabilities. Journal of experimental child psychology, 93(3), (2006) 265-281. http://dx.doi.org/10.1016/j.jecp.2005.08.003

[40] Blackwell,K., Cepeda,N., \& Munakata,Y.: When simple things are meaningful: Working memory strength predicts children's cognitive flexibility. Journal of Experimental Child Psychology 103, (2009) 241-249. http://dx.doi.org/10.1016/j.jecp.2009.01.002

[41] Steele, M. M.: Making the case for early identification and intervention for young children at risk for learning disabilities. Early Childhood Education Journal, 32(2), (2004), 75-79. http://dx.doi.org/10.1007/s10643-004-1072-x

[42] Engel de Abreu, P., Conway, A., \& Gathercole, S.: Working memory and fluid intelligence in young children. Intelligence 38 , (2010) 552-564. http://dx.doi.org/10.1016/j.intell.2010.07.003

[43] Galecka, J. : How Technology Helped Create National Standards for Early and Special Needs Education (2012).

[44] Klingberg, T., Fernell, E., Olesen, P. J., Johnson, M., Gustafsson, P., Dahlström, K., \& Westerberg, H.: Computerized training of working memory in children with ADHD-a randomized, controlled trial. Journal of the American Academy of Child \& Adolescent Psychiatry, 44(2), (2005) 177-186. http://dx.doi.org/10.1097/00004583-200502000-00010

[45] Holmes, C.: An Intergenerational Program with Benefits. Early Childhood Education Journal 37,(2009) 113-119. http://dx.doi.org/10.1007/s10643-009-0329-9

[46] Baddeley, A.: The episodic buffer: a new component of working memory? Trends in cognitive sciences, 4(11), (2000) 417-423. http://dx.doi.org/10.1016/S1364-6613(00)01538-2

[47] Shalev, L., Tsal, Y., Mevorach, C.: Computerized Progressive Attentional Training (CPAT) Program: Effective Direct Intervention for Children with ADHD. Child Neuropsychology, 13, (2007) 382-389. http://dx.doi.org/10.1080/09297040600770787

[48] Mezzacappa, E., \& Buckner, J. C.: Working memory training for children with attention problems or hyperactivity: A school-based pilot study. School Mental Health, 2(4), (2010) 202-208. http://dx.doi.org/10.1007/s12310-010-9030-9

\section{AUTHORS}

Athanasios Drigas is a Senior Researcher at N.C.S.R. Demokritos. He is the Coordinator of Telecoms Lab and founder of Net Media Lab since 1996. From 1985 to 1999 he was the Operational manager of the Greek Academic network. He has been the Coordinator of Several International Projects, in the fields of ICTs, and e-services (elearning, e-psychology, e-government, e-inclusion, eculture etc). He has published more than 200 articles, 7 books, 25 educational CD-ROMs and several patents. He has been a member of several International committees for the design and coordination of Network and ICT activities and of international conferences and journals. (e-mail: dr@iit.demokritos.gr).

Georgia Kokkalia (MSc in Specific Learning Difficulties) is a Special Education Teaching Professional. She has participated in various research projects regarding the use of Information and Communication Technologies (ICTs) in Special Education and in Kindergarten. (e-mail: gioulina@hotmail.com).

Submitted 30 December 2014. Published as resubmitted by the authors 30 October 2015. 